\title{
Study on Temperature Effect of Concrete Mechanical Properties
}

\author{
Maotong Li \\ College of Water Conservancy and \\ Civil Engineering \\ Shandong Agricultural University \\ Tai' an City, China \\ Leemaotong@163.com \\ Yuanchao Zhou \\ College of Water Conservancy and \\ Civil Engineering \\ Shandong Agricultural University \\ Tai'an City, China \\ 1141224318@qq.com
}

\author{
Chuanxiao Liu* \\ College of Water Conservancy and \\ Civil Engineering \\ Shandong Agricultural University \\ Tai'an City, China \\ Lchuanx@163.com
}

Jiashu Liang

College of Water Conservancy and

Civil Engineering

Shandong Agricultural University

Tai'an City, China

1358332400@qq.com

\author{
Huaqing Yang \\ College of Water Conservancy and \\ Civil Engineering \\ Shandong Agricultural University \\ Tai'an City, China \\ 752936051@qq.com
}

\begin{abstract}
Taking Plain Concrete column and Reinforced Concrete column for research objects, the uniaxial compression experiments were carried out to fix baking time, change temperature and fix temperature, change baking time. Numerical simulation was performed using FLAC3D software and all experimental data were collected for analysis. In the same baking time, the higher the temperature, the smaller the elasticity modulus of theplain concrete column and reinforced concrete column, the peak strength decreased gradually and the peak strain increased gradually; the residual strength of plain concrete column decreased, and the residual strength of reinforced concrete column increased gradually. With the temperature increasing, the dehydration shrinkage of cement paste and the thermal expansion of aggregate lead to the increase of micro cracks in the interface, which weakens the strength of concrete. At the same baking temperature, with the increase of baking time, the peak strength of plain concrete column and reinforced concrete column increased first and then decreased, and the residual strength was smaller. With the bound water out of cement gel, the cementing effect of cement particles was enhanced, eased the stress concentration on the seam, which is conducive to improve the concrete strength. The elastic modulus of plain concrete column decreased gradually. the elastic modulus of reinforced concrete column increase gradually; the peak strain of the plain concrete column is gradually increasing, the peak strain of the reinforced concrete column decreases. Because the concrete expansion coefficient is small, the concrete squeeze steel bar, the bond strength between steel and concrete is improved.
\end{abstract}

Keywords-- concrete column, temperature effect, mechanical properties, uniaxial compression, FLAC ${ }^{3 D}$

\section{INTRODUCTION}

The application of concrete as a main building material in engineering construction has a long history. The reinforced concrete structure combines the respective performance advantages of steel and concrete, and has the advantages of low cost, and is widely used in civil buildings, industrial buildings, roads, and bridges., dams, coastal and offshore structures, defense structures, and other related fields. Concrete and reinforced concrete structures are the main structures of most modern buildings. The study of their performance under a certain temperature will help to explore the stability and safety of concrete and reinforced concrete structures under temperature. Concrete and reinforced concrete are multiphase composite materials, and there are many factors affecting their mechanical properties, which leads to complex changes in various performance indicators after experiencing different temperature effects. Hightemperature workshops of metallurgical and chemical companies, chimneys that emit high-temperature flue gas, mine mining lanes affected by underground temperatures, nuclear reactor pressure vessels, and containment structures all experience long-term temperature effects. The degree of temperature, the length of the temperature effect will have different degrees of impact on the mechanical properties of concrete buildings.

The stress-strain relationship of concrete under compression is an important part of the mechanical properties of concrete. The stress-strain curve of concrete under uniaxial stress is the most widely used in structural analysis. By analyzing the shape of the stress-strain curve of the concrete under compression, a series of mechanical parameters can be obtained during the compression process, and then the various deformation processes such as brittleness, plasticity, yielding, and fracture occurring under external forces can be reflected. This article takes plain concrete columns and reinforced concrete column specimens as the research object. After the temperature treatment, the uniaxial compression test is carried out to obtain the stressstrain curve of each test specimen. The numerical simulation is performed using FLAC3D software and the obtained experimental data are collected. Analyze and obtain the change law of the elastic modulus, peak strength, peak strain and residual strength of the specimen at different temperatures.

\section{PREPARATION OF CONCRETE SPECIMENS}

Concentrated procurement of wood, PVC plastic pipe, plastic paper, black iron wire, but also according to the test requirements of the PVC pipe processing, production of 200 uniform specifications of the mold (inner diameter $50 \mathrm{~mm}$, 
vertical height $100 \mathrm{~mm}$ ). River sand and general portland cement numbered 32.5 were purchased in the building materials market. Specimen production uses concrete mixers, electronic scales, $1000 \mathrm{ml}$ and $500 \mathrm{ml}$ measuring cylinders, square hole aggregate standard sieves, mortar submergence testers, shovels, iron buckets, weighing trays, and experimental calculation instruments.

After the specimens were finished, they were cured. The conditions were alkaline water environment and constant temperature maintenance. The ambient temperature was maintained at about $5-10^{\circ} \mathrm{C}$. The conditions were close to the environmental conditions in the basic application. The curing time exceeded the normal strength test period ( 28 days). The development is basically close to the peak and meets the stress-strain study conditions. After the specimen reaches a certain strength, the specimen is removed from the mold and the mold is removed after the mold is removed to maintain its strength.

In order to study the temperature effect of the mechanical properties of concrete columns and reinforced concrete columns, the experiment was designed as A and B groups, each group consists of 4 groups. Each group consists of a plain concrete column and a reinforced concrete column. In the reinforced concrete column, the steel wires were placed crosswise vertically, and 4 pieces of $8.5 \mathrm{~cm}$ were placed vertically and 2 layers were placed horizontally. Each piece had 2 pieces of $4.2 \mathrm{~cm}$. All specimens were $50 \mathrm{~mm}$ in diameter and $100 \mathrm{~mm}$ in height with a mass ratio of $\mathrm{C}: \mathrm{S}: \mathrm{W}=1: 3.95: 0.68$.

\section{EXPERIMENTAL DESIGN}

The FX101-3 electric blast drying oven developed by Shanghai Water Conservancy Instrument, which is equipped with the Water Conservancy Civil Engineering Test Center of Shandong Agricultural University, is used for drying articles, drying heat treatment and other heat treatment. The drying box is provided with a viewing window, which can observe the heating of the articles in the working room at any time. Can use a variety of temperature control instruments, high temperature control accuracy, good stability. The hot air circulation system consists of continuous operation of fans and air ducts at high temperatures, and the temperature in the working chamber is uniform. Baking temperature range: room temperature $+10{ }^{\circ} \mathrm{C} \sim+250{ }^{\circ} \mathrm{C}$, to meet the baking requirements of concrete specimens.

The SAW-2000 microcomputer-controlled electrohydraulic servo rock triaxial testing machine developed by Changchun Kexin Test Instrument Co., Ltd. configured in the Water Conservancy Civil Engineering Experimental Center of Shandong Agricultural University, It is mainly used for uniaxial compression tests, triaxial compression tests, relaxation tests, and low-period pulsation tests of rock, concrete, and cement mortar specimens. Three sets of DOLI company's EDC controller and MOOG ' s D633 proportional servo valve were used to complete the whole process of the experiment, achieving automatic control and data acquisition. The stiffness of the testing machine reaches $2 \times 10^{10} \mathrm{~N} / \mathrm{m}$, and the response frequency is fast, which can fully meet the mechanical test requirements of concrete specimens.

In this test, both A and B specimens will be baked first. In group $\mathrm{A}$, the samples of different groups were baked at $50^{\circ} \mathrm{C}, 100^{\circ} \mathrm{C}, 150^{\circ} \mathrm{C}$, and $200^{\circ} \mathrm{C}$, respectively. The baking time was 2 days. The group B samples were uniformly determined to have a baking temperature of $100^{\circ} \mathrm{C}$. The test pieces of the group were baked for 5 days, 10 days, 15 days, and 20 days. After the baking was completed, it was naturally cooled to normal temperature, and a uniaxial compression test was performed in time to obtain a compressive stress-strain curve for each test piece. Through the analysis of the stress-strain curve, the elastic modulus, peak strength, peak strain and residual strength of each set of test specimens are obtained.

\section{TEST RESULTS}

For each group of baked concrete samples, the uniaxial compression test was performed to obtain the stress-strain curve. The mechanical parameters such as elastic modulus and peak strength of each test piece were calculated and calculated. The software was used under the same conditions using the Origin software. The various mechanical parameters are compiled into a graph, and then the change law of the mechanical properties of concrete specimens under different temperatures is obtained.

\section{A. Test result of group A}

Four groups of specimens in group A were baked continuously for two days. The baking temperatures were $50^{\circ} \mathrm{C}, 100^{\circ} \mathrm{C}, 150^{\circ} \mathrm{C}$, and $200^{\circ} \mathrm{C}$, respectively. After the baking, the natural cooling was performed and the uniaxial compression test was performed. The stress-strain curves of plain concrete columns and reinforced concrete columns are shown in Fig.1-2.

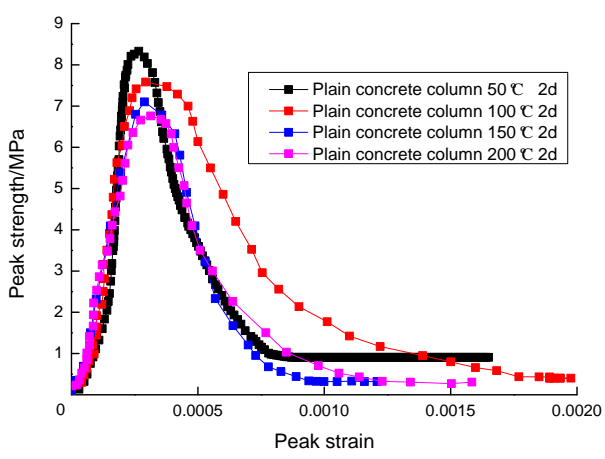

Fig.1. Stress-strain curve of plain concrete columns of group A

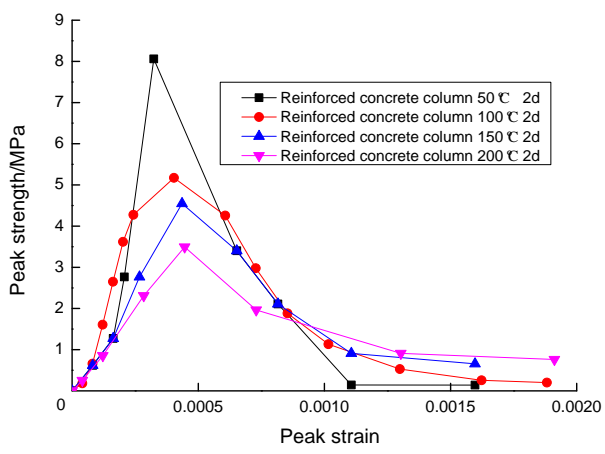

Fig.2. Stress-strain curve of reinforced concrete columns of group A 
The original state of Group A specimens and the state after pressure destruction are shown in Fig.3.

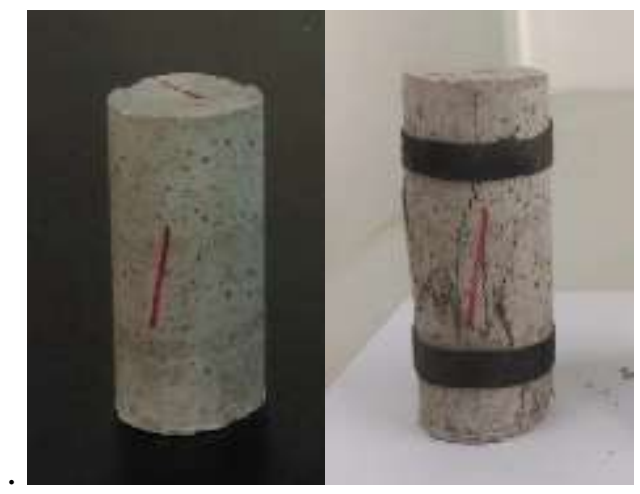

$50^{\circ} \mathrm{C} 2 \mathrm{~d}$ Plain concrete column

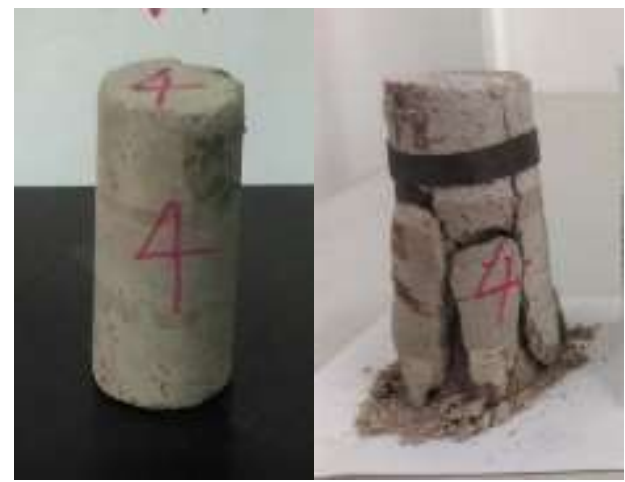

$100^{\circ} \mathrm{C} 2 \mathrm{~d}$ Plain concrete column

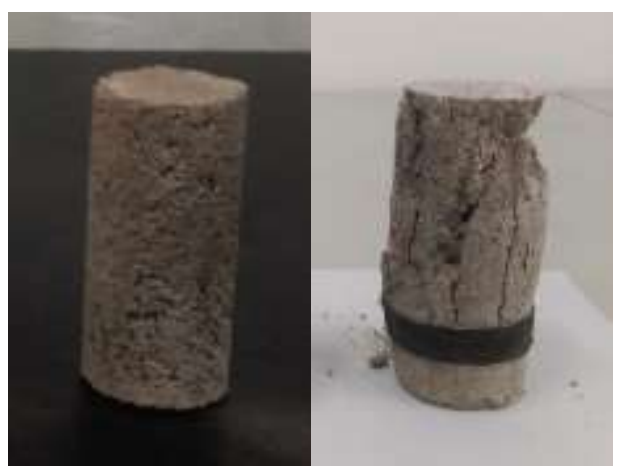

$150^{\circ} \mathrm{C} 2 \mathrm{~d}$ Plain concrete column

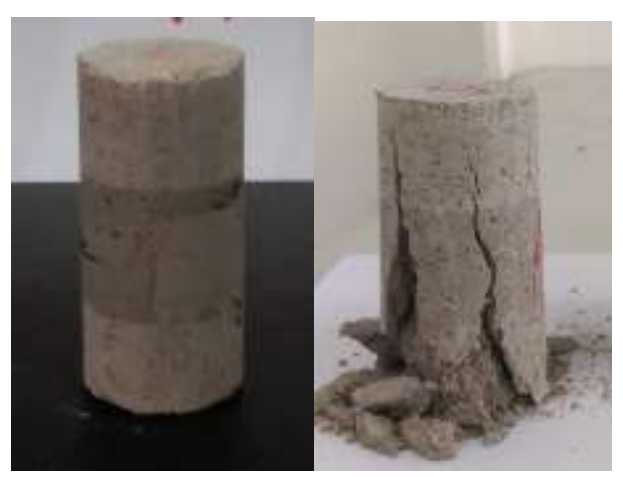

$200^{\circ} \mathrm{C} 2 \mathrm{~d}$ Plain concrete column

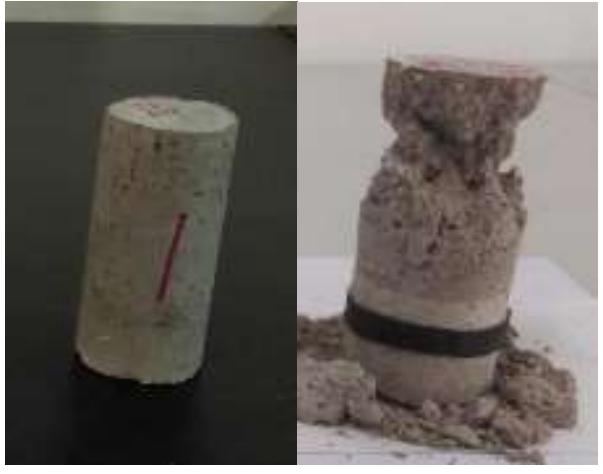

$50^{\circ} \mathrm{C} 2 \mathrm{~d}$ Reinforced concrete column

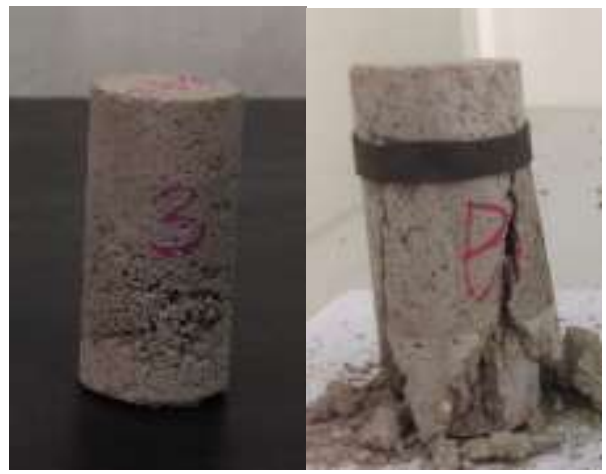

$100^{\circ} \mathrm{C} 2 \mathrm{~d}$ Reinforced concrete column

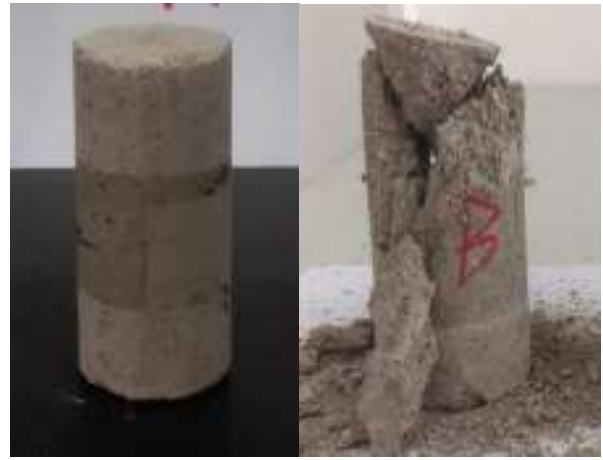

$150^{\circ} \mathrm{C} 2 \mathrm{~d}$ Reinforced concrete column

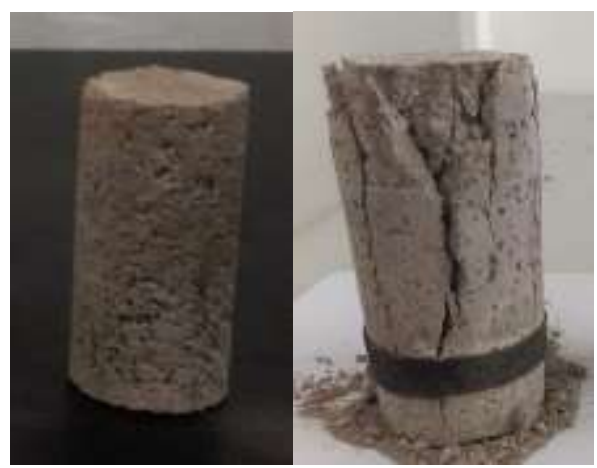

$200^{\circ} \mathrm{C} 2 \mathrm{~d}$ Reinforced concrete column

Fig.3. The original state of Group A specimens and the state after pressure destruction 


\section{B. $\quad$ Test result of group $B$}

The baking temperature of the four groups in the group B was $100^{\circ} \mathrm{C}$, and the baking time was 5 days, 10 days, 15 days and 20 days, respectively. After the baking, the natural cooling was performed and the uniaxial compression test was performed. The stress-strain curves of plain concrete columns and reinforced concrete columns are shown in Fig.4-5.

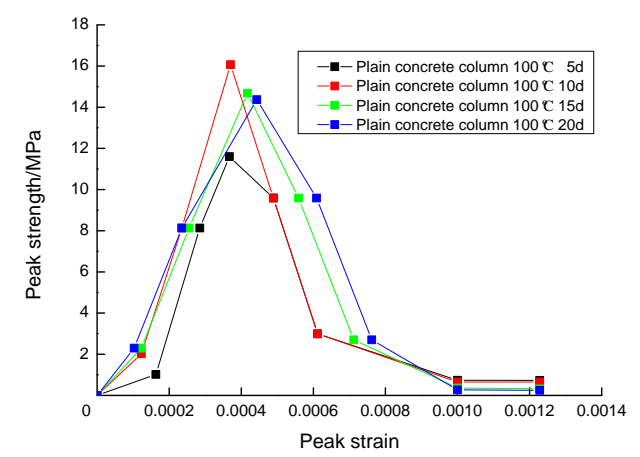

Fig.4. Stress-strain curve of plain concrete columns of group B

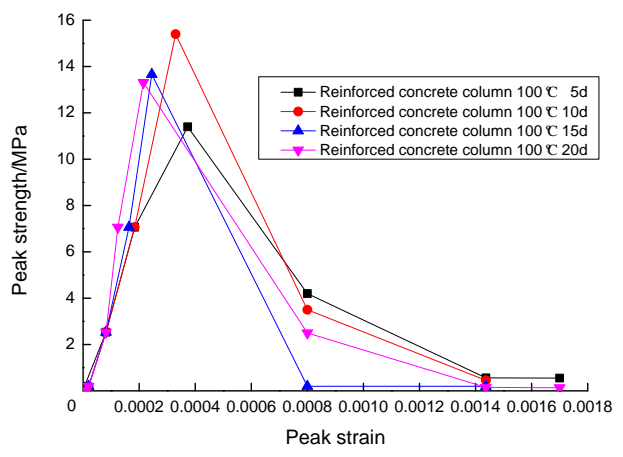

Fig.5. Stress-strain curve of reinforced concrete columns of group B

The original state of Group A specimens and the state after pressure destruction are shown in Fig. 6.

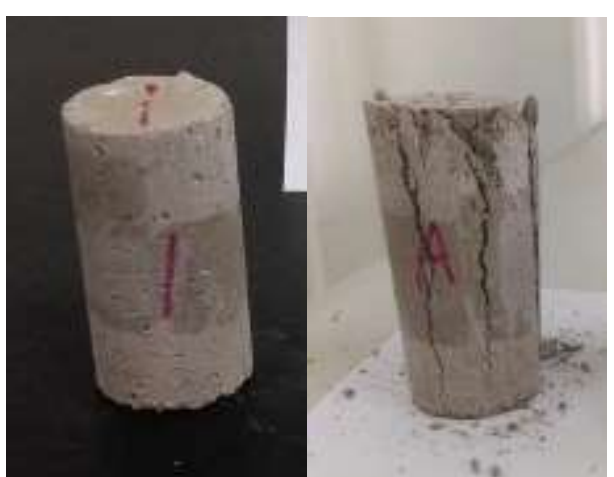

$100^{\circ} \mathrm{C} 5 \mathrm{~d}$ Plain concrete column

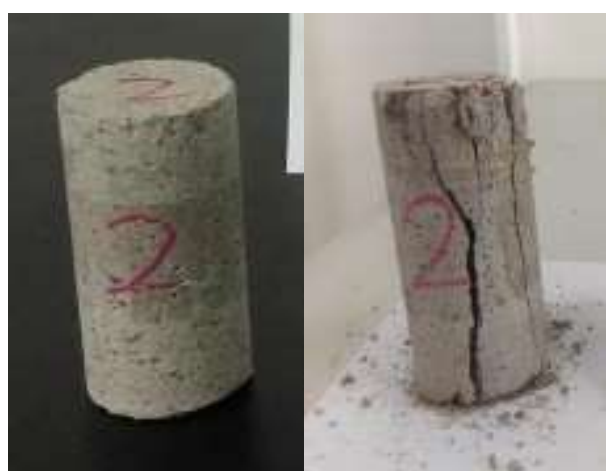

$100^{\circ} \mathrm{C} 10 \mathrm{~d}$ Plain concrete column

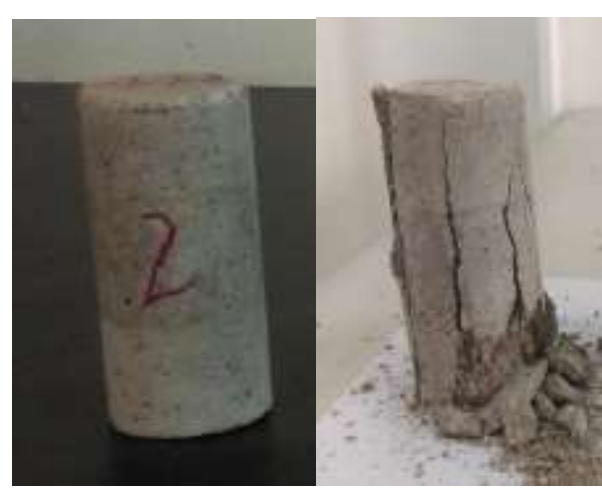

$100^{\circ} \mathrm{C} 15 \mathrm{~d}$ Plain concrete column

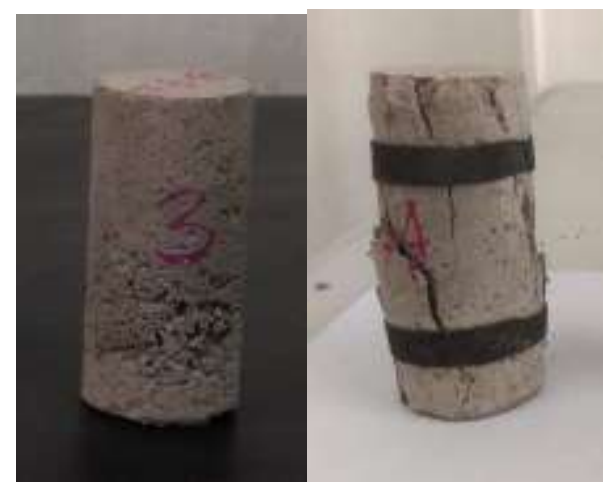

$100^{\circ} \mathrm{C} 20 \mathrm{~d}$ Plain concrete column 


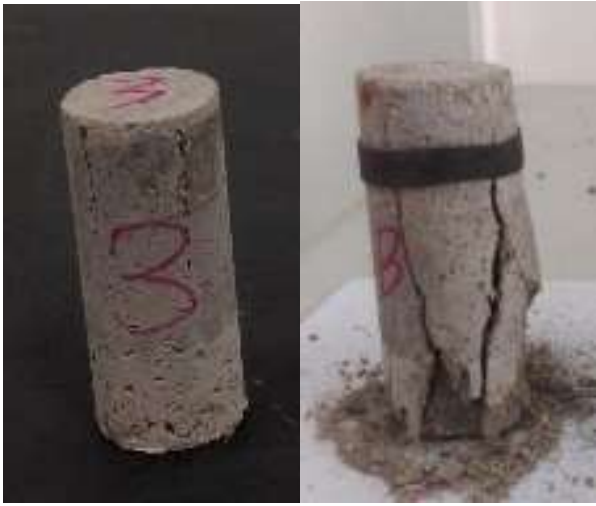

$100^{\circ} \mathrm{C} 5 \mathrm{~d}$ Reinforced concrete column

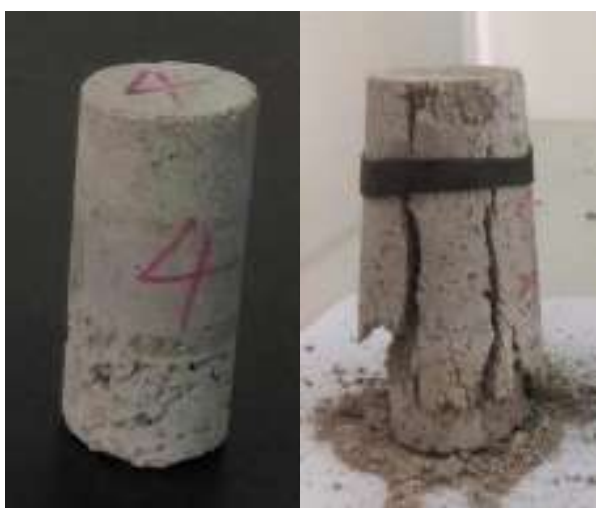

$100^{\circ} \mathrm{C} 10 \mathrm{~d}$ Reinforced concrete column

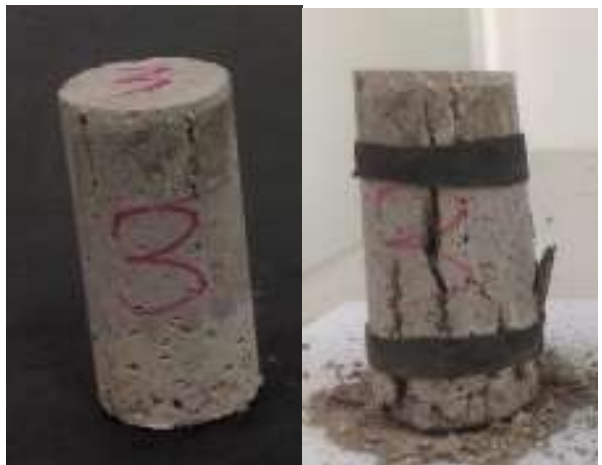

$100^{\circ} \mathrm{C} 15 \mathrm{~d}$ Reinforced concrete column

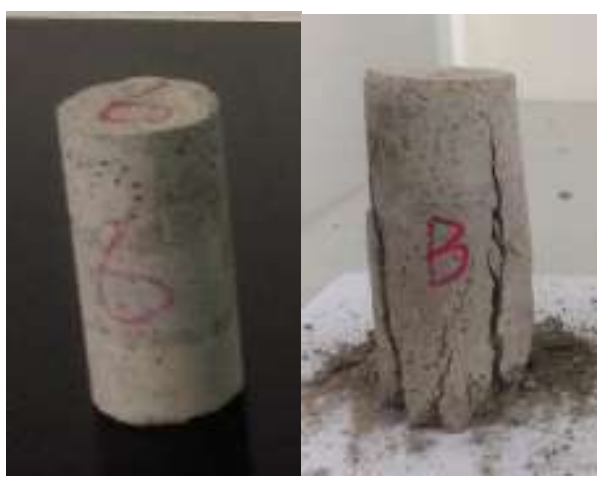

$100^{\circ} \mathrm{C} 20 \mathrm{~d}$ Reinforced concrete column

Fig.6. The original state of Group B specimens and the state after pressure destruction

\section{NUMERICAL SIMULATION}

FLAC $^{3 \mathrm{D}}$ software was used for numerical analysis and the model was tested using a strain hardening/softening model and a cylindrical grid. The test piece height was uniformly set to $0.1 \mathrm{~m}$, and the test piece diameter was $0.05 \mathrm{~m}$. According to the mechanical properties of concrete specimens at room temperature, the basic parameters such as bulk modulus $\mathrm{K}$ and shear modulus $\mathrm{G}$ were determined, and then different experimental conditions were applied to simulate the temperature effect.

\section{A. Numerical simulation scheme}

The numerical simulation was divided into two groups, C, $\mathrm{D}$, respectively, the first heat treatment test model respectively: $\mathrm{C}$ group fixed baking time of 2 days, baking temperature were $250{ }^{\circ} \mathrm{C}, 300{ }^{\circ} \mathrm{C}, 350{ }^{\circ} \mathrm{C}, 400{ }^{\circ} \mathrm{C}$; D group to determine Baking temperature is $100{ }^{\circ} \mathrm{C}$, baking time is 25d, 30d, 35d, 40d. Uniaxial compression tests were performed on each test piece after heat treatment to obtain stress-strain curves for each test piece.

\section{B. Numerical simulation results}

The stress-strain curve of Group C specimens is shown in Fig.7-8.

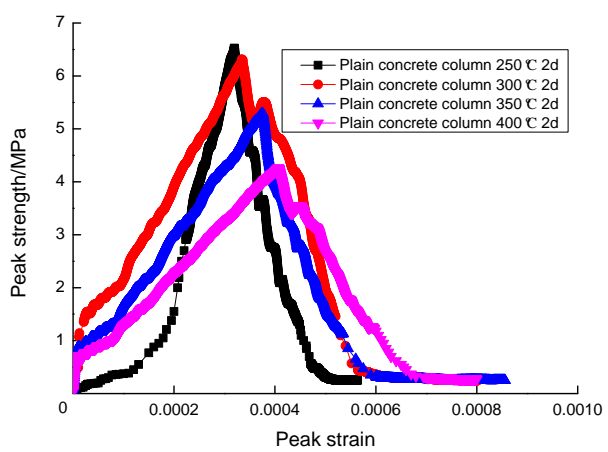

Fig.7. Stress-strain curve of plain concrete specimens

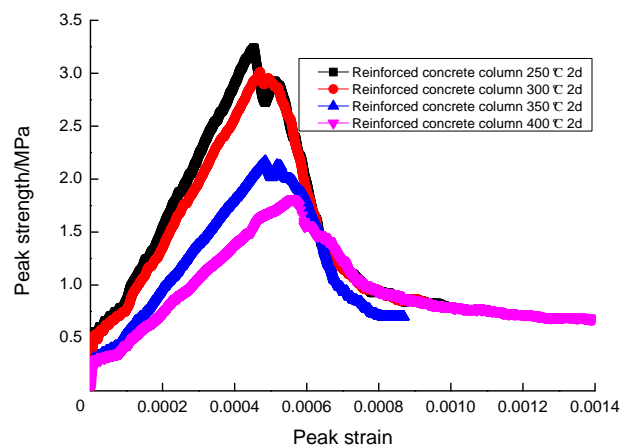

Fig.8. Stress-strain curve of reinforced concrete specimens

The stress-strain curve of Group $\mathrm{C}$ specimens is shown in Fig.9-10. 


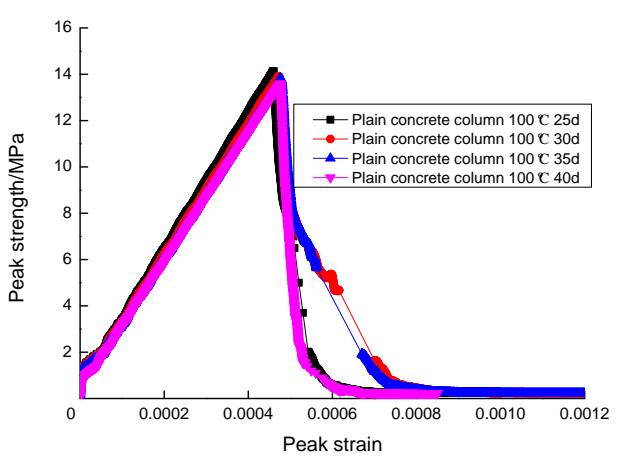

Fig.9. Stress-strain curve of plain concrete specimens

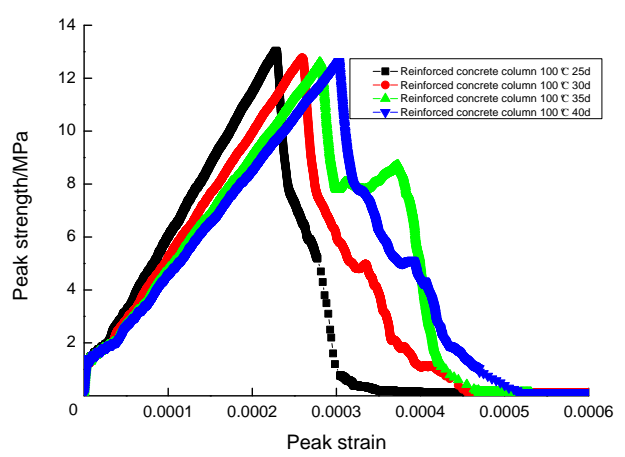

Fig.10. Stress-strain curve of reinforced concrete specimens

\section{COMPREHENSIVE ANALYSIS}

Combine group $\mathrm{A}$ and group $\mathrm{C}$ into group $\mathrm{E}$. Combine group B and group D into group F. Summarize the test data. Use Origin software to plot the elastic modulus, peak intensity, peak strain, and residual of the two groups of specimens. The change curve of the strength is analyzed to obtain the change rule of each mechanical property under different temperature conditions.

The change law of elastic modulus in Group E is shown in Fig.11.

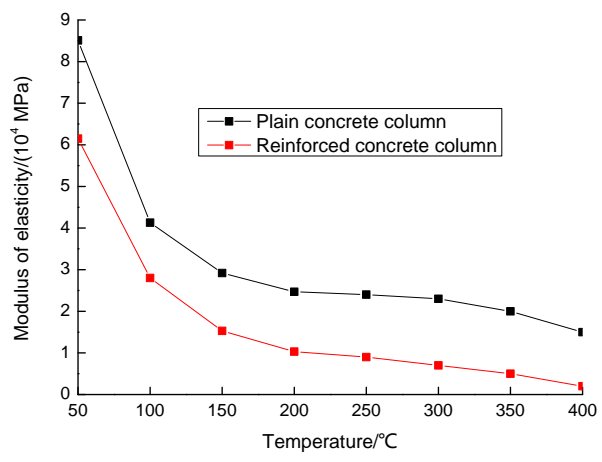

Fig.11. The change law of elastic modulus in Group E

It can be seen from the figure that as the temperature rises, the elastic modulus of plain concrete specimens and reinforced concrete specimens gradually decreases, and the elastic modulus of plain concrete specimens as a whole is larger than that of reinforced concrete specimens. Under the condition of heating for 2 days, the temperature rises from $50^{\circ} \mathrm{C}$ to $400^{\circ} \mathrm{C}$, and the elastic modulus of the plain concrete specimens decreases by $51.47 \%, 29.30 \%, 15.41 \%, 4.17 \%$, $13.04 \%$, and $25 \%$, respectively; the reinforced concrete test The elastic modulus of the pieces decreased by $54.47 \%$, $45.36 \%, 32.68 \%, 22.22 \%, 28.57 \%$, and $60 \%$ in turn. The average elastic modulus of the concrete specimens is $42.53 \%$ higher than that of the reinforced concrete specimens. After the temperature is higher than $200^{\circ} \mathrm{C}$, the decrease rate of the elastic modulus of the two specimens gradually decreases. With the increase of temperature, the syneresis of the cement paste and the thermal expansion of the aggregate lead to the increase of the micro cracks at the interface, which reduces the stiffness of the concrete.

The change law of elastic modulus in Group $\mathrm{F}$ is shown in Fig.12.

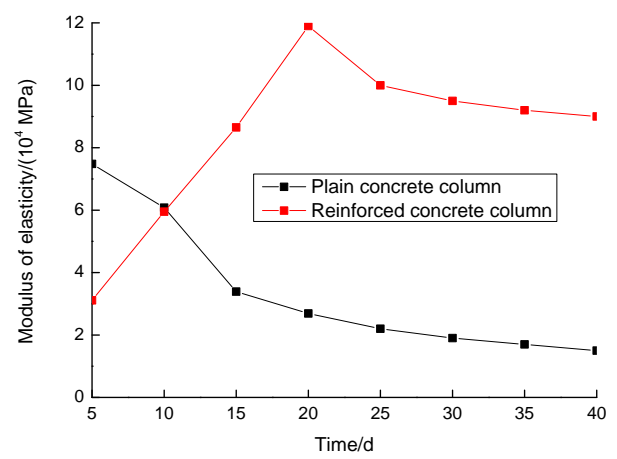

Fig.12. The change law of elastic modulus in Group F

It can be seen from the figure that the heating time increases from 5 days to 40 days at a temperature of $100^{\circ} \mathrm{C}$. The elastic modulus of the plain concrete specimens decreases by successively by $18.72 \%, 44.24 \%, 20.65 \%$, $13.64 \%, 10.53 \%$, and $11.76 . \%$, the syneresis of the cement paste and the thermal expansion of the aggregate lead to the increase of micro cracks at the interface, weakening the strength of the concrete, the descending rate is greater on the 10 th to 15 th days, and the elastic modulus of the reinforced concrete column increases sequentially by $91.32 \%$. , $45.39 \%$, $37.57 \%$, reached the maximum in about 20 days, and then decreased by $5 \%, 3.16 \%$, and $2.17 \%$ in turn; the elastic modulus of both was about the same as in the 10th day. The coefficient of thermal expansion of the concrete is smaller than that of the steel bar, so that the concrete is pressed against the steel bar to increase the adhesion between the steel bar and the concrete, and the elastic modulus of the reinforced concrete increases.

The change of peak strength in group $\mathrm{E}$ is shown in Fig.13. 


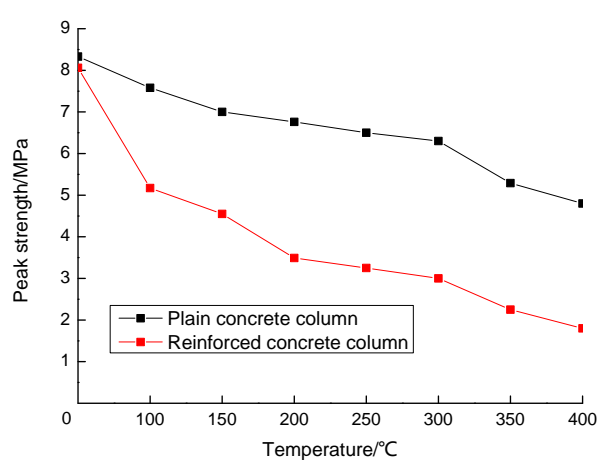

Fig.13. The change of peak strength in group $\mathrm{E}$

It can be seen from the figure that the peak strength of the plain concrete and reinforced concrete specimens gradually decreases as the temperature rises for 2 days. The temperature rises from $50^{\circ} \mathrm{C}$ to $400^{\circ} \mathrm{C}$. The peak strength of plain concrete specimens slowly decreases, decreasing by $9.00 \%, 7.65 \%, 3.43 \%, 3.08 \%, 16.03 \%$, and $9.26 \%$, respectively; the peak strength of reinforced concrete specimens decreases in turn. $35.86 \%, 11.99 \%, 23.30 \%$, $7.69 \%, 25 \%, 20 \%$. As the baking temperature increases, the aggregate deforms and the dewatering of the cement slurry causes micro cracks between the aggregate and the cement slurry, and the performance of the concrete is further reduced. At the same time, the properties of steel bars in concrete decrease as the temperature increases, reducing the overall strength.

The change of peak strength in group $F$ is shown in Fig.14.

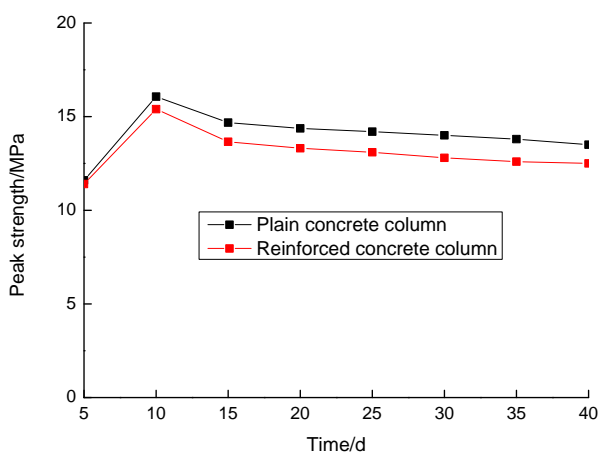

Fig.14. The change of peak strength in group $\mathrm{F}$

It can be seen from the figure that the heating time is increased from 5 days to 40 days at a temperature of $100^{\circ} \mathrm{C}$. The peak strengths of plain concrete and reinforced concrete specimens increase first and then decrease. The peak strength of plain concrete specimens is high. Reinforced concrete. The peak strength of plain concrete specimens first increased by $38.53 \%$, and then decreased by $8.65 \%, 2.11 \%, 1.41 \%$, $1.43 \%$, and $2.17 \%$, respectively; the peak strength of reinforced concrete specimens first increased by $35.09 \%$, and then decreased by $11.3 \%$. $2.56 \%, 2.29 \%, 1.56 \%, 0.79 \%$, the maximum value on the 10th day. Before the 10th day, the bound water in the cement gel began to come out, which enhanced the cementation of the cement particles, eased the stress concentration at the seam end, and was beneficial to the improvement of the concrete strength. Decreased slowly after the 10th day, the syneresis of the cement paste and the thermal expansion of the aggregate led to the increase of micro cracks at the interface, and the strength of the concrete weakened.

The change of peak strain in group $\mathrm{E}$ is shown in Fig.15.

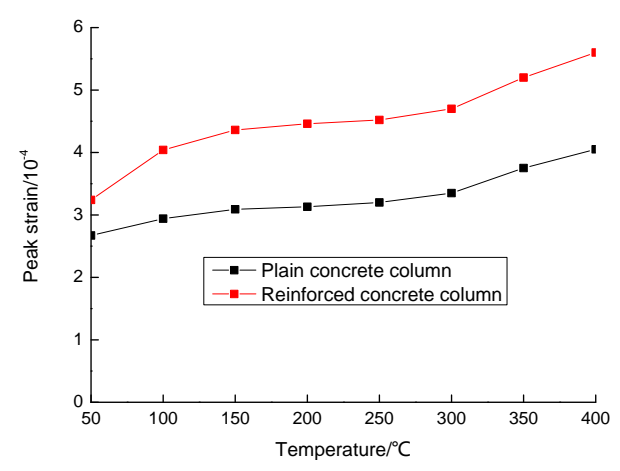

Fig.15. The change of peak strain in group E

As can be seen from the figure, the heating temperature rises from $50^{\circ} \mathrm{C}$ to $400^{\circ} \mathrm{C}$ for 2 days, and the peak strain of plain concrete specimens increases by $10.11 \%, 3.06 \%$, $3.30 \%, 4.69 \%, 11.94 \%$, and $8 \%$, respectively; the peak strain of reinforced concrete specimens increased by $24.69 \%$, $7.92 \%, 2.29 \%, 3.98 \%, 10.64 \%$, and $7.69 \%$, respectively. During the natural cooling of the specimen after baking, the deformation of the aggregate gradually recovers and the dehydration of the cement slurry cannot be resumed, which further expands the micro-cracks between the aggregate and the cement slurry, further degrades the performance of the concrete and increases the peak strain. .The bond strength between steel and concrete decreases, making the average peak strain value of reinforced concrete specimens $29.8 \%$ higher than that of plain concrete specimens.

The change of peak strain in group $\mathrm{F}$ is shown in Fig. 16.

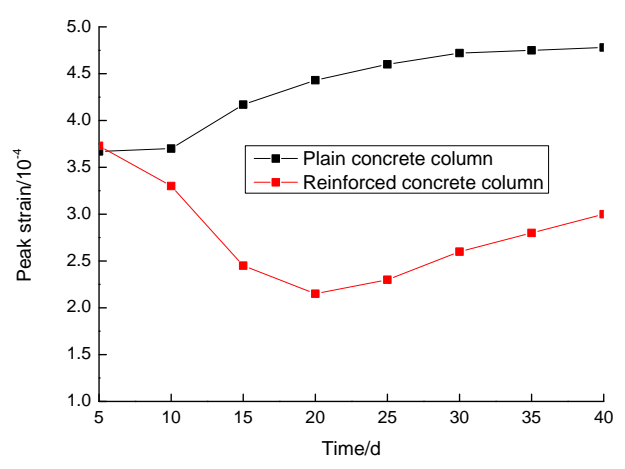

Fig.16. The change of peak strain in group $\mathrm{F}$

As can be seen from the figure, the baking time increases from 5 days to 40 days at a temperature of $100^{\circ} \mathrm{C}$, and the peak strain of plain concrete specimens increases by $0.82 \%$, $10 \%, 8.85 \%, 2.61 \%, 0.64 \%, 0.63 \%$ in sequence. The peak strain of reinforced concrete specimens decreased by $11.53 \%$, $25.76 \%$, and $16.73 \%$ in turn, and then increased by $13.04 \%$, $7.69 \%$, and $7.14 \%$ in 20 days. With the increase of the time, the bound water in the cement gel began to come out, which enhanced the cementation of the cement particles, eased the 
stress concentration at the joint, and increased the peak strain. The aggregates in the reinforced concrete are deformed and the cement slurry is dehydrated, causing cracks between the aggregates and the steel bars and reducing the peak strain.

The change of residual strength in group $\mathrm{E}$ is shown in Fig. 17.

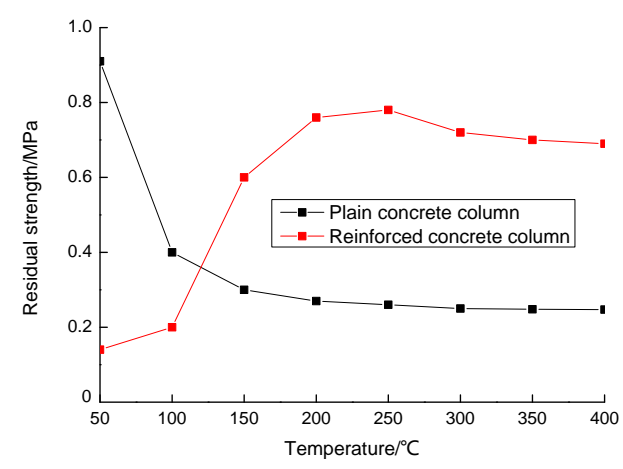

Fig.17. The change of residual strength in group E

As can be seen from the figure, the heating temperature rises from $50^{\circ} \mathrm{C}$ to $400^{\circ} \mathrm{C}$ for 2 days, and the residual strength of the plain concrete column decreases by $56.04 \%$, $20 \%, 15.63 \%, 3.85 \%, 0.8 \%, 0.4 \%$, respectively, after $100^{\circ} \mathrm{C}$. The influence weakened; the residual strength of the reinforced concrete specimens increased by $42.86 \%, 200 \%$, and $26.67 \%$ in turn, and the turning point was $250{ }^{\circ} \mathrm{C}$, followed by a decrease of $7.69 \%, 2.78 \%$, and $1.43 \%$. The syneresis of the cement paste and the thermal expansion of the aggregate lead to increased microcracks at the interface, weakening the strength of the plain concrete. As the coefficient of thermal expansion of the concrete is small, the concrete is pressed against the steel bar to increase the bond strength between the steel bar and the concrete, thereby increasing the residual strength of the reinforced concrete.

The change of residual strength in group $\mathrm{F}$ is shown in Fig.18.

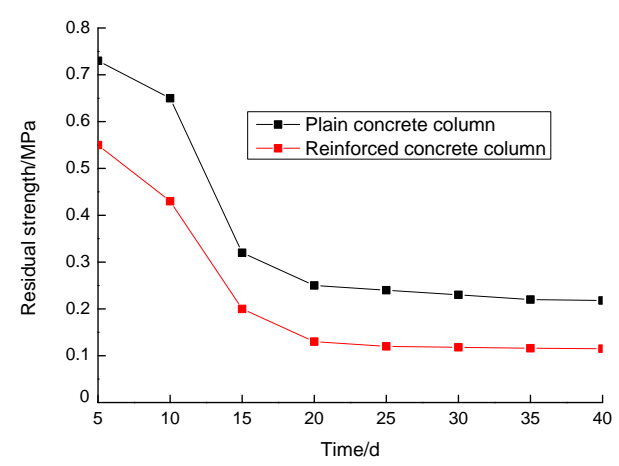

Fig.18. The change of residual strength in group $\mathrm{F}$

As can be seen from the figure, the baking time increases from 5 days to 40 days at a temperature of $100^{\circ} \mathrm{C}$. The residual strength of the plain concrete specimens decreases by $10.96 \%, 50.77 \%, 21.88 \%, 4.17 \%, 4.35 \%, 0.91 \%$, respectively. The residual strength of reinforced concrete specimens decreased by $21.82 \%, 48.84 \%, 40.91 \%, 1.67 \%$, $1.69 \%$, and $0.86 \%$, respectively. The residual strength of plain concrete and reinforced concrete specimens both drastically decreased, reaching a minimum around the 20th day, and then gradually approaching the level; the residual strength of plain concrete specimens was generally higher than that of reinforced concrete. Over time, the syneresis of the cement paste and the thermal expansion of the aggregate lead to increased microcracks at the interface, weakening the strength of the concrete.

\section{MAIN CONCLUSIONS}

The elastic modulus of plain concrete and reinforced concrete decreases sharply with the increase of temperature under the condition of heating for 2 days, and the decreasing amplitude gradually decreases after $200{ }^{\circ} \mathrm{C}$, and the corresponding peak strain increases gradually; The peak strength of plain concrete decreases slowly with increasing temperature, and the peak strength of reinforced concrete decreases more. When the temperature rises, the syneresis of the cement paste and the thermal expansion of the aggregate lead to increased microcracks at the interface, weakening the strength of the concrete.

The longer the constant-temperature heating of the concrete and reinforced concrete at $100^{\circ} \mathrm{C}$, the greater the peak strength of the two at first, the maximum at the 15 th day, and then the slow decrease. The bound water in the cement gel begins to come out, which enhances the cementation of the cement particles, eases the stress concentration at the seam end, and is beneficial to the improvement of the concrete strength; the residual strength of the two cements is greatly reduced, and the decreasing rate gradually becomes smaller. Continuous baking causes the syneresis of the cement paste and the thermal expansion of the aggregate to cause micro cracks at the interface to increase, weakening the strength of the concrete.

The longer the initial temperature of the concrete at $100^{\circ} \mathrm{C}$, the smaller the elastic modulus, the greater the drop before the 25th day, and the greater the peak strain, while the elastic modulus of the reinforced concrete is gradually increased. The maximum value was reached around the 25 th day; the peak strain gradually decreased, decreased to the minimum value on the 25th day, and then gradually increased. The residual strength of plain concrete decreases significantly with the increase of temperature, and the decreasing amplitude becomes smaller and smaller, while the residual strength of reinforced concrete increases significantly. Under heating conditions, due to the small expansion coefficient of the concrete, the concrete is pressed against the steel bar to increase the adhesion between the steel bar and the concrete, increasing the toughness of the reinforced concrete, and increasing the elastic modulus and residual strength.

\section{ACKNOWLEDGMENT}

This paper finished under the guidance of tutor Liu Chuanxiao, and was supported by the Key Research and Development Project of Shandong Province (No. 2018GNC110023), the Natural Science Foundation of Shandong Province (No. ZR2014DM019) and the National Natural Science Foundations of China (No. 51574156, 51004098). 


\section{REFERENCES}

[1] Lu Tianqi, Zhao Guofan, Lin Zhishen, "Experimental study on mechanical properties of concrete after high temperature",Journal of architectural structure, vol 25, pp. 63-70, January 2004.

[2] Shi Xudong, Guo Zhenhai, "Experimental study on mechanical behavior of reinforced concrete frame under high temperature",China Civil Engineering Journal, vol 6, pp. 12-17, January 2000.

[3] Yan Jihong, Lin Zhishen, Hu Yunchang, "Experimental study on compressive strength of concrete after high temperature",China Civil Engineering Journal, vol.23, pp. 17-19, March 2002.

[4] Wu Bo, "Mechanical properties of reinforced concrete structures after fire", Science Press, 2003.

[5] Jing Denghu, Cao Shuangyan, "Practice of engineering structure identification and reinforcement and Reconstruction Technology",Southeast University press, vol 20, pp. 160-162, June 2015.

[6] Zhou Songsheng, Zhou Lu,Lu Zhen, "New construction technology manual", Anhui Science and Technology Press, vol 30, pp. 10031004, June 2006
[7] Chen Lei, Li Bin, "Analysis of mechanical properties of concrete at high temperature", Concrete, vol 10, pp. 26-28, June 2003.

[8] Qin Likun, Song Yupu, Wang Yujie, "Experimental study on the influence of high temperature on the mechanical properties of concrete", Concrete, vol 32, pp. 9-11, May 2005.

[9] Yuan Guanglin, Guo Cao, "Test and analysis of the bond behavior of reinforced concrete at high temperature", Industrial buildings, vol.27, pp. 57-60, February 2006.

[10] $\mathrm{Li} \mathrm{Li,} \mathrm{Hu} \mathrm{Haitao,} \mathrm{"Review} \mathrm{of} \mathrm{research} \mathrm{on} \mathrm{high} \mathrm{temperature}$ performance of reinforced concrete structures", Journal of Qingdao Institute of Architecture and Engineering, vol 25, pp.33-38, February 2004.

[11] Lin M., Qian C.X., Sun W, "Mechanical properties of high-strength after fire", Cement Concrete Research, vol 34, pp. 1001-1005, June 2004.

[12] Du Feng, Xiao Jianzhuang, Gao Xiangling, "Study on the test method of bond between steel bar and concrete", Structural engineer, vol 22, pp. 93-97, May 2006. 